\title{
An Investigation into the Enhancement of Condensate Recovery from Retrograde Gas Condensate Reservoirs
}

\author{
H.R. Nasriani ${ }^{\text {* }}$, K. Khan 1 , A. Nematizadeh Haghighi², M.R. Rafiee ${ }^{3}$, T. Graham ${ }^{1}$, S. Ndlovu${ }^{1}$, \\ J. Mai ${ }^{1}$, M. Aran ${ }^{2}$ \\ ${ }^{1}$ University of Central Lancashire; ${ }^{2}$ Marvdasht Azad University; ${ }^{3}$ Jahrom University
}

H. R. Nasriani, K. Khan, A. N. Haghighi, M. R. Rafiee, T. Graham, and S. Ndlovu, "An Investigation into the Enhancement of Condensate Recovery from Retrograde Gas Condensate Reservoirs," in 81st EAGE Conference and Exhibition 2019, 2019, vol. 2, no. June 2019, pp. 3-7.

DOI: $10.3997 / 2214-4609.201901313$

\section{Summary}

The loss in condensate recovery from gas condensate reservoirs due to condensate dropout when the flowing bottom hole pressure drops below the dew point pressure of the in-situ reservoir fluid is significant. Pressure maintenance and gas cycling are the standard practices used to alleviate this problem and enhance the condensate and gas recoveries.

In this study, swelling and constant volume depletion tests are conducted on the original fluid sample from a gas condensate reservoir. Various scenarios regarding gas injection recycling are examined to determine the most appropriate gas for injection which enhances gas and condensate recovery. In this study, injection of three gases (CO2, N2 and separator gas) with different injection volumes on the current field fluid were tested using simulation.

Based on the results of this study, $\mathrm{CO} 2$ was the most efficient gas followed by separator gas and N2 respectively to inject into the gas condensate reservoirs for decreasing the condensate dropout and enhancing its recovery.

This result is significant as $\mathrm{CO} 2$ injection in gas condensate reservoirs could be used to sequestrate the produced $\mathrm{CO} 2$ from power plants and other sources while enhancing the production from gas condensate reservoirs. 


\section{Introduction}

The injection of dry gas $\left(\mathrm{N}_{2}, \mathrm{CO}_{2}\right.$, or $\left.\mathrm{CH}_{4}\right)$ into a retrograde gas-condensate reservoir evaporates condensate and increases the dew-point pressure of the reservoir fluid. The results of experiments showed that injection of dry gas could vaporize both intermediate and some heavy hydrocarbons (Luo et al., 2001; Nasriani et al., 2014; Nasiri Ghiri et al., 2015; Nasriani, Borazjani, et al., 2015). It was also shown that dry gas injection into gas condensate reservoirs results in enrichment of the dry gas due to mass transfer.

It was found that full pressure maintenance yielded a higher condensate recovery than partial pressure maintenance (Li et al., 2001; Nasriani, Asadi, et al., 2015, 2017; Nasriani, Borazjani, et al., 2015; Zareenejad et al., 2015; Nasriani et al., 2016; MoradiDowlatAbad et al., 2017; Nasriani, MoradiDowlatAbad, et al., 2017).

Boersma \& Hagoort (1994) compared displacement characteristics of nitrogen and methane injection into volatile oil reservoirs based on phase behaviour analysis, compositional reservoir simulation, and slim-tube experiments. Nitrogen has been applied in gas injection due to its economic feasibility (Eckles Jr et al., 1981; Huang et al., 1986).

Sanger \& Hagoort (1998) investigated the efficiency of nitrogen to evaporate gas-condensate compared to methane using a slim tube. The recovery of nitrogen injection reached $94 \%$, but it decreased when the pressure is lowered below the dew-point pressure. They also found that methane re-evaporated the condensate and resulted in complete recovery of all condensate. The recovery of condensate was found to be more sensitive to dispersion during nitrogen injection than that during methane flooding. They recommended using nitrogen for gas injection based on availability and cost.

In this study, different gas recycling scenarios were investigated using swelling and constant volume depletion (CVD) tests data of the reservoir fluid. The best scenario of fluid injection for enhancing the condensate/Gas recovery were selected. In this study, different gas injection scenarios in a PVT Cell on the current field fluid were tested with three injection gases $\left(\mathrm{CO}_{2}, \mathrm{~N}_{2}\right.$ and separator gas) with different injection volumes of 250, 500, 750, 1000, 1500, 2000 (SCF).

\section{Swelling Test Simulation of the Original Fluid}

Swelling test data was required to investigate the fluid behaviour by injection of gas into the gas condensate reservoir to find the best injection fluid, the effect of injection volumes and the optimum pressure. Since this information could not be achieved from the samples of the tested wells of the field, it was decided to simulate the swelling test. $\mathrm{N}_{2}, \mathrm{CO}_{2}$ and separator gas of the field were used to define the most appropriate injection gas.

\section{Simulation of Swelling Test by $\mathbf{N}_{2}$ Injection}

For the first scenario, $\mathrm{N}_{2}$ was injected into the initial reservoir fluid. The changes in saturation pressure and swelling factor (SF) of each injection volume were investigated. Figure 1 shows the results of swelling test for $\mathrm{N}_{2}$ injection in the injection volumes of 250, 500, 750, 1000, 1500 and 2000 SCFs per a barrel of fluid. Therefore, the corresponding gas oil ratio (GOR) values are from 0.25 to 2 (MSCF/STB) respectively.

As illustrated in Figure 1, the higher the $\mathrm{N}_{2}$ injection volume is, the lower the saturation pressure of the fluid sample (reservoir fluid) and the higher the swelling factor are. In this graph, the saturation pressure of injection volume of 2000 SCF per a barrel of fluid has changed from $5092 \mathrm{psi}$ at the original value to $3890 \mathrm{psi}$ after the injection. Swelling factor of the aforementioned injection volume is 3.29. This means that the saturation volume of $\mathrm{N}_{2}$ and reservoir fluid of this injection volume is 3.29 times larger than the saturation volume of original fluid of the reservoir. This has happened because the original fluid becomes lighter after injection of $\mathrm{N}_{2}$.

\section{Simulation of Swelling Test by $\mathrm{CO} 2$ Injection}

In the second scenario, $\mathrm{CO}_{2}$ was investigated. Similar approach was conducted using $\mathrm{CO}_{2}$ and the changes in saturation pressure and swelling factor of the six mentioned volumes were inspected.

Figure 1 shows the results of swelling test for the $\mathrm{CO}_{2}$ injection for injection volumes of 250,500, 750, 1000, 1500 and $2000 \mathrm{SCFs}$, per a barrel of initial reservoir fluid. 
As shown in the Figure 1, an increase in $\mathrm{CO}_{2}$ injection volume results in reduction of the saturation pressure of the fluid sample and an increase in the swelling factor. According to the Figure 1, for instance, for injection volume of 2000 SCF per a barrel of fluid, the saturation pressure declines from $5092 \mathrm{psi}$ (original dew-point pressure) to $1993 \mathrm{psi}$. Also, swelling factor of the injection volume of 2000 $\mathrm{SCF}$ is 5.54. In other words, the saturation volume of $\mathrm{CO}_{2}$ and reservoir fluid, at injection volume of $2000 \mathrm{SCF}$, is 5.54 times larger than the saturation volume of the original fluid. This increase is due to the fact that the original fluid becomes lighter after $\mathrm{CO}_{2}$ injection.

\section{Simulation of Simulation of Swelling Test by Separator Gas Injection}

In the third scenario, the gas from the first stage of separator was used for the injection. Figure 1 shows the results of swelling test after the injection of separator gas. These injection volumes are as the same as those used in the previous sections. As it is shown in the Figure 1, the saturation pressure of new fluid has decreased and the swelling factor has increased by increase in the injection volume of the separator gas.

In this Figure, the saturation pressure of a barrel of the reservoir fluid decreased from 5092 to 2819 psi for the injection volume of 2000 SCF. Also, swelling factor of this volume was calculated 3.88. In other words, the saturation volume of the separator gas for injection volume of 3.88 equals the saturation volume of the original reservoir fluid. These results are presented in Figure 1.

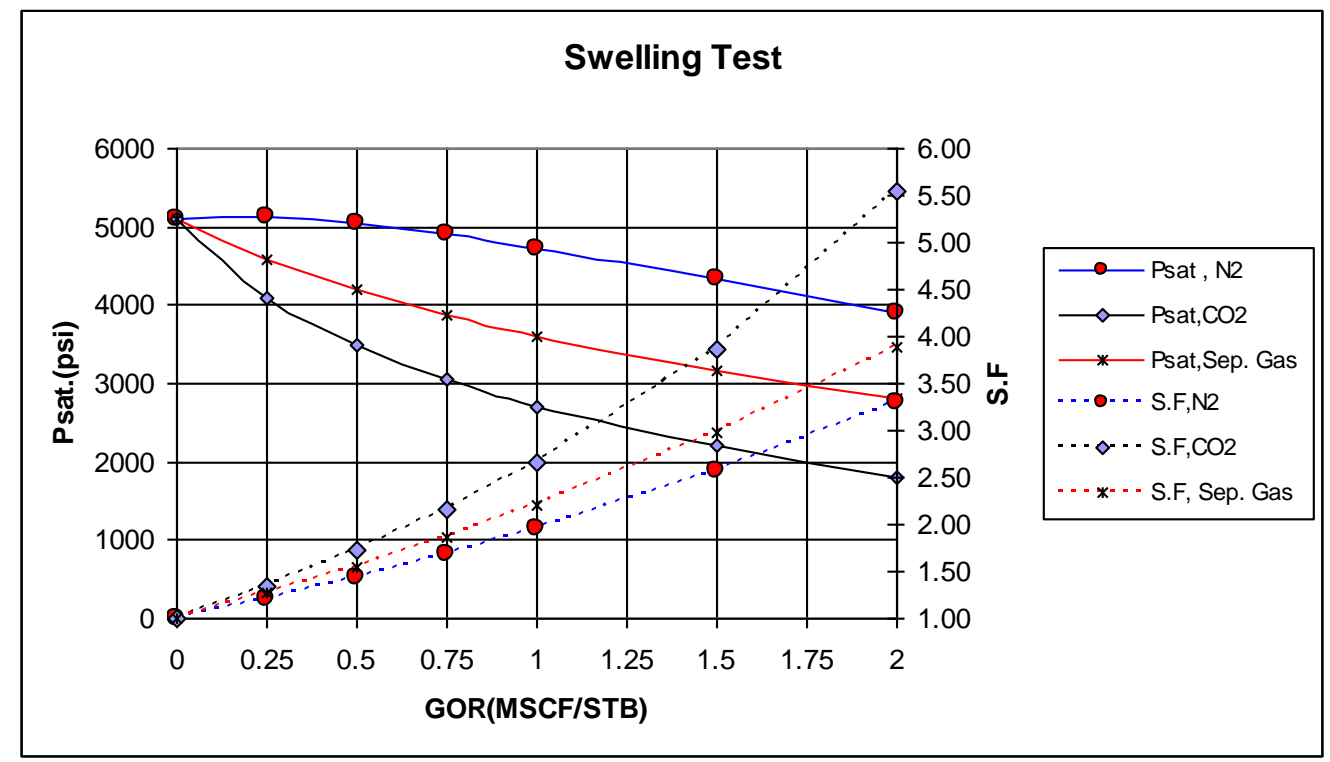

Figure 1: Swelling Test results in Different Injection Rate from 250 to 2000 SCF per a Reservoir Barrel

From Figure 1, it should be noted that $\mathrm{CO}_{2}$ is the most effective gas for injection to decrease the reservoir fluid's saturation pressure. The injection of $\mathrm{CO}_{2}$ consequently delivered the largest swelling factor for this case. Based on this result, the separator gas and $\mathrm{N}_{2}$ were chosen as the second and third candidates for gas injection strategy in this reservoir respectively.

\section{Simulation of Constant Volume Depletion of the Current Reservoir Fluid}

The constant volume depletion (CVD) test was simulated in order to study the effect of different gas injection volumes on condensate re-vaporization. The CVD test is modelled for each gas at different injection volumes while the formation of liquid dropout has been monitored.

\section{$\mathrm{N}_{2}$ Injection}

For the first scenario, the amount of condensate dropout during natural depletion was studied during the different stages of pressure drop of the current fluid of the reservoir (natural depletion). Then, the amount of condensate dropouts when injecting $\mathrm{N}_{2}$ into PVT Cells with different volumes (i.e., 250, 500, $750,1000,1500$ and 2000 SCFs) were measured and compared with the natural depletion scenario. For injection volumes greater than $750 \mathrm{SCF}$, the resulting fluid was dry gas and no condensate was formed. 
Figure 2 shows the degree of liquid dropout formation at different stages of pressure reduction with various $\mathrm{N}_{2}$ injection volumes. As seen in this Figure, the amount of liquid dropout changes from $0.6 \%$ at original state to $0.16 \%$ for injection volume $500 \mathrm{SCF}$, (Figure 2).

\section{$\mathrm{CO}_{2}$ Injection}

At this stage, $=\mathrm{CO}_{2}$ with volumes of $250,500,750,1000,1500$ and 2000 SCF per a barrel of reservoir fluid are injected. The amount of condensate dropouts are then calculated and compared with the natural depletion. At injection volumes larger than $250 \mathrm{SCF}$, the resulting fluid was dry gas. As shown in the Figure 2, the amount of liquid dropout changed from $\% 0.6$ (natural depletion) to $\% 0.12$ for injection $250 \mathrm{SCF}$ of $\mathrm{CO}_{2}$.
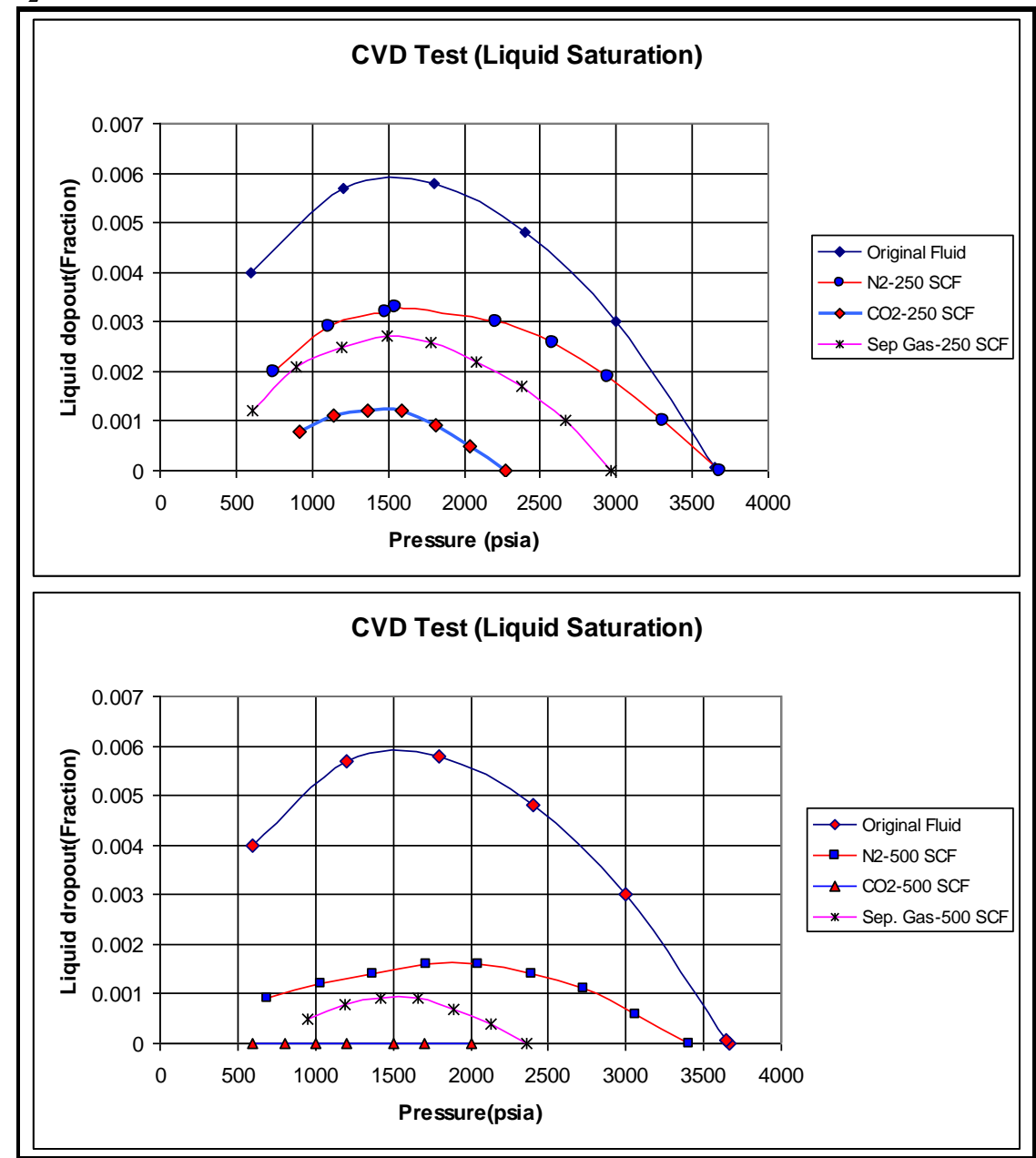

Figure 2 The effect of $\mathrm{N} 2, \mathrm{CO} 2$ and separator gas injections on the decrease of liquid formation at injection volume 250 SCF and 500 SCF

\section{Separator Gas injection}

Finally, the separator gas was considered. No liquid dropout was formed for the injection volumes more than 500 SCF. As shown in Figure 2, the amount of liquid dropouts has changed from \%0.6 at original state to \%0.1 at injection volume of $500 \mathrm{SCF}$.

As both three gas resulted in the dry gas fluid in volumes more than 500 SCF, only the volumes of 250 and 500 SCF were shown in Figure 2. As it could be seen in this Figure, $\mathrm{CO}_{2}$ was the most effective gas to reduce of the condensate dropout. The separator gas was the second and $\mathrm{N}_{2}$ was the last effective gas for injection respectively. The decrease of liquid formation of all injection gases was remarkable and no liquid was formed at injection volumes more than 500 SCF.

\section{Conclusions}

Based on these observations we can conclude the following:

- The results of the swelling test and CVD test reveal that injecting gas reduces the condensate dropout.

- The higher the of injection volume is, the larger decrease in condensate formation will happen. 
- $\mathrm{CO}_{2}$, separator gas and $\mathrm{N}_{2}$ decreased the condensate dropout respectively in the simulated CVD test.

- In current condition of the reservoir, there was no liquid formation at different stages of pressure depletion related to the injection with volumes larger than 500 SCF per a barrel of the reservoir fluid for all injection gases in the simulated CVD test.

- These results are only based on the study of the reservoir fluid. It is necessary to study the impacts of the porous media (of the reservoir) together with other possible involved internal phenomena. This might affect this results.

- Although the reservoir fluid is lean, gas injection plays a significant role in condensate dropout reduction and improves the production parameters which could be impaired by liquid dropouts banking around the well.

\section{References}

Boersma, D. M. and Hagoort, J. (1994) 'Displacement characteristics of nitrogen flooding vs. methane flooding in volatile oil reservoirs', SPE Reservoir Engineering. 9(04), pp. 261-265.

Eckles Jr, W. W., Prihoda, C. and Holden, W. W. (1981) 'Unique enhanced oil and gas recovery for very high-pressure Wilcox sands uses cryogenic nitrogen and methane mixture', Journal of Petroleum Technology. Society of Petroleum Engineers, 33(06), pp. 971-984.

Huang, W. W., Bellamy, R. B. and Ohnimus, S. W. (1986) 'A study of nitrogen injection for increased recovery from a rich retrograde gas/volatile oil reservoir', Society of Petroleum Engineers.

Li, S., Zheng, X., Dai, Z., Luo, K., Chen, G. and Liu, N. (2001) 'Investigation of revaporization of retrograde condensate', in SPE Middle East Oil Show. Society of Petroleum Engineers.

Luo, K., Li, S., Zheng, X., Chen, G., Liu, N. and Sun, W. (2001) 'Experimental investigation into revaporization of retrograde condensate', in SPE Production and Operations Symposium.

MoradiDowlatAbad, M., Nasriani, H. R., Rashidi, F. and Movahedi, M. (2017) 'Modelling and performance evaluation of gas condensate reservoirs-inclusion of porous media properties', in 79th EAGE Conference and Exhibition 2017.

Nasiri Ghiri, M., Nasriani, H. R., Sinaei, M., Najibi, S. H., Nasriani, E. and Parchami, H. (2015) 'Gas Injection for Enhancement of Condensate Recovery in a Gas Condensate Reservoir', Energy Sources, Part A: Recovery, Utilization, and Environmental Effects, 37(8), pp. 799-806. doi: 10.1080/15567036.2011.596901.

Nasriani, H. R., Asadi, E., Johnson, C., Nasriani, M. and Chamchine, A. (2016) 'Estimation of In-situ Compositions in Lean Gas Condensate Reservoirs', in ECMOR XIV-15th European Conference on the Mathematics of Oil Recovery.

Nasriani, H. R., Asadi, E., Khan, K., Graham, T. L., Ndlovu, S. and Mai, J. (2017) 'Evaluation of insitu compositions in retrograde gas condensate fields', in 79th EAGE Conference and Exhibition 2017. Nasriani, H. R., Asadi, E., Nasiri, M., Khajenoori, L. and Masihi, M. (2015) 'Challenges of Fluid Phase Behavior Modeling in Iranian Retrograde Gas Condensate Reservoirs', Energy Sources, Part A: Recovery, Utilization, and Environmental Effects. Taylor \& Francis, 37(6), pp. 663-669. doi: 10.1080/15567036.2011.594865.

Nasriani, H. R., Borazjani, A. A., Iraji, B. and MoradiDowlatAbad, M. (2015) 'Investigation into the effect of capillary number on productivity of a lean gas condensate reservoir', Journal of Petroleum Science and Engineering. Elsevier, pp. 384-390.

Nasriani, H. R., Borazjani, A. A., Sinaei, M. and Hashemi, A. (2014) 'The Effect of Gas Injection on the Enhancement of Condensate Recovery in Gas Condensate Reservoirs: A Comparison Between a Synthetic Model and PVT Cell Results', Petroleum Science and Technology, 32(5), pp. 593-601. doi: 10.1080/10916466.2011.596890.

Nasriani, H. R., MoradiDowlatAbad, M., Borazjani, A. A. and Nasriani, M. (2017) 'On the Revaporization of Retrograde Condensate by Gas Injection', 79th EAGE Conference and Exhibition.

Sanger, P. J. and Hagoort, J. (1998) 'Recovery of gas-condensate by nitrogen injection compared with methane injection', SPE Journal. Society of Petroleum Engineers, 3(01), pp. 26-33.

Zareenejad, M. H., Kalantariasl, A., Nasriani, H. R. and Zargar, G. (2015) 'Analysis and Comparison of Decline Models: A Field Case Study of a Naturally Fractured Gas Condensate Reservoir', Energy Sources, Part A: Recovery, Utilization, and Environmental Effects, 37(4), pp. 392-400. doi: 10.1080/15567036.2011.576409. 